\title{
Outcome prediction in sepsis: Speckle tracking echocardiography based assessment of myocardial function
}

\author{
Sam R Orde ${ }^{1,2}$, Juan N Pulido ${ }^{3}$, Mitsuru Masaki ${ }^{4}$, Shane Gillespie ${ }^{3}$, Jocelyn N Spoon ${ }^{1}$, Garvan C Kane ${ }^{1}$
} and Jae $\mathrm{KOh}^{1 *}$

\begin{abstract}
Introduction: Speckle tracking echocardiography (STE) is a relatively novel and sensitive method for assessing ventricular function and may unmask myocardial dysfunction not appreciated with conventional echocardiography. The association of ventricular dysfunction and prognosis in sepsis is unclear. We sought to evaluate frequency and prognostic value of biventricular function, assessed by STE in patients with severe sepsis or septic shock.
\end{abstract}

Methods: Over an eighteen-month period, sixty patients were prospectively imaged by transthoracic echocardiography within 24 hours of meeting severe sepsis criteria. Myocardial function assessment included conventional measures and STE. Association with mortality was assessed over 12 months.

Results: Mortality was $33 \%$ at 30 days $(n=20)$ and $48 \%$ at 6 months $(n=29) .32 \%$ of patients had right ventricle (RV) dysfunction based on conventional assessment compared to $72 \%$ assessed with STE. 33\% of patients had left ventricle (LV) dysfunction based on ejection fraction compared to 69\% assessed with STE. RV free wall longitudinal strain was moderately associated with six-month mortality (OR 1.1, 95\% confidence interval, $\mathrm{Cl}, 1.02-1.26, \mathrm{p}=0.02$, area under the curve, AUC, 0.68). No other conventional echocardiography or STE method was associated with survival. After adjustment (for example, for mechanical ventilation) severe RV free wall longitudinal strain impairment remained associated with six-month mortality.

Conclusion: STE may unmask systolic dysfunction not seen with conventional echocardiography. RV dysfunction unmasked by STE, especially when severe, was associated with high mortality in patients with severe sepsis or septic shock. LV dysfunction was not associated with survival outcomes.

\section{Introduction}

Characterized by hemodynamic distress, severe sepsis is frequently associated with cardiopulmonary dysfunction driven by a cascade of cellular and molecular processes [1]. Myocardial dysfunction occurs frequently, early and involves both ventricles [2,3]. Whether myocardial dysfunction is related to outcome is unclear and may in part be related to the definition and modality of assessment. Echocardiography plays a crucial role in the noninvasive assessment of cardiac function in the ICU [4], but the optimal measure of ventricular dysfunction, particularly for the right ventricle (RV), has not been well established.

\footnotetext{
* Correspondence: oh.jae@mayo.edu

'Division of Cardiovascular Diseases, Mayo Clinic, 200 First St SW, Rochester, MN 55905, USA

Full list of author information is available at the end of the article
}

Interpretation of changes in volumetric measures such as fractional area change (FAC) or ejection fraction can be affected by swings in volume status and loading conditions, frequent features in sepsis, and may not reflect well underlying contractility. Furthermore, such measures may lack sensitivity.

Two-dimensional speckle tracking echocardiography (STE) has emerged as an angle-independent technique for quantifying systolic function by assessing myocardial deformation [5,6]: strain and strain/time (strain rate). STE has been shown to be a feasible and sensitive quantitative technology for assessing ventricular contractile function in a variety of different cardiovascular diseases such as chemotherapy-induced cardiotoxicity [7], amyloidosis [8,9], preeclampsia [10] and in a pediatric cohort with severe sepsis [11]. The main focus of STE has been 
left ventricle (LV) global longitudinal strain (GLS), reflecting the function of the subendocardial myocardial fibers, which are oriented longitudinally. These fibers are especially sensitive to ischemia and increased wall stress [12]. STE has potentially even greater applicability to the quantitative assessment of RV function. Distinct from the LV, the RV has a preponderance of longitudinal fibers and therefore a greater proportion of contractility of the RV occurs from base to apex [13]. Longitudinal STE is hence well poised to act as a robust measure of RV contractility: RV free wall strain and RV free wall strain rate.

The objectives of this study were to assess: the prevalence of RV and LV dysfunction in severe sepsis and septic shock assessed with STE; factors related to RV and LV longitudinal strain dysfunction; and whether myocardial dysfunction assessed by STE is associated with mortality at 30 days and 6 months.

\section{Methods}

We prospectively studied 60 adult patients ( $>18$ years) with severe sepsis or septic shock admitted over an 18month period at St. Mary's Hospital, Rochester, MN, USA. The study was approved by the Mayo Institutional Review Board and written consent was obtained from all patients or authorized representatives (next of kin) before enrollment. Individuals were included by American College of Chest Physicians criteria for severe sepsis or septic shock [14]. Sepsis was defined by two or more criteria: temperature $>38^{\circ} \mathrm{C}$ or $<36^{\circ} \mathrm{C}$, heart rate $>90$ beats/ minute, respiratory rate $>20$ breaths/minute or arterial partial pressure of carbon dioxide $<32$ Torr $(<4.3 \mathrm{kPa})$, white cell count $>12,000$ cells $/ \mathrm{mm}^{3},<4,000$ cells $/ \mathrm{mm}^{3}$, or $>10 \%$ immature (band) forms. Severe sepsis was defined as sepsis associated with organ dysfunction (Sequential Organ Failure Assessment (SOFA) score $\geq 2$ ), hypoperfusion (lactate $>2.3 \mathrm{mmol} / \mathrm{dl}$, our institutional high normal value) or hypotension (systolic blood pressure $<90 \mathrm{mmHg}$ or decreased $40 \mathrm{mmHg}$ below baseline). Severe sepsis with hypotension resistant to intravenous fluids was considered septic shock. Exclusion criteria were supraventricular tachyarrhythmias, pregnancy, congenital heart disease, cardiomyopathy, moderate or severe valvular disease and valvular prosthesis and insufficient image quality for STE.

\section{Echocardiography}

Transthoracic echocardiography was performed within 24 hours of meeting sepsis criteria with a Vivid 7 echocardiography machine (GE Medical Systems, Milwaukee, WI, USA) by research sonographers or research fellows fully trained in echocardiography and strain imaging. A comprehensive echocardiogram was performed according to American Society of Echocardiography guidelines [15].
Physiologic parameters were recorded at the time of echocardiography. LV systolic dysfunction was classified by ejection fraction: present $(<55 \%)$ or absent $(>55 \%)$, and mild ( 45 to $54 \%$ ), moderate (30 to $44 \%$ ) or severe $(<30 \%)$. The RV was assessed at end expiration in a multimodal fashion as per American Society of Echocardiography guidelines (tricuspid annular plane systolic excursion, lateral tricuspid annular velocity, RV wall motion, FAC) [16] and was classified as normal, mild, moderate or severe dysfunction. Parameters for abnormal RV systolic function were defined as tricuspid annular plane systolic excursion $<16 \mathrm{~mm}, \mathrm{FAC}<35 \%$, Tricuspid valve systolic motion velocity $<10 \mathrm{~cm} /$ second or reduced RV wall motion. For severe dysfunction, RV wall motion was severely reduced and/or FAC was $<17 \%$ [16]. RV size was measured - basal, mid and longitudinal dimensions (abnormal above 42 $\mathrm{mm}, 35 \mathrm{~mm}$ and $86 \mathrm{~mm}$ respectively) - and compared with the LV size. Images were analyzed by physicians fully trained in echocardiography (MM, JKO, JNP).

\section{Speckle tracking echocardiography analysis}

Three-beat two-dimensional digital clips were transferred to a Syngo Velocity Vector Imaging workstation (Siemens Medical Solutions USA Inc., Pleasanton, CA, USA) for STE analysis by SRO, who had performed more than 100 hours of analysis in STE prior to commencing the study. The endocardium was traced manually from the medial annulus with 7 to 15 points. $\mathrm{LV}$ values were averages of the $16 \mathrm{LV}$ segments. If STE could not be calculated on one apical view, the LV was considered to have insufficient image quality. RV values were an average of the three free wall segments. Once accuracy of tracking was ensured, displacement, velocity, strain and strain rate curves were assessed for motion, smoothness, time to peak, delay and correlation (Figure 1a, b). The same cardiac cycle was chosen for STE values. All images were analyzed three times to ensure accuracy of results. Strain and strain rate are negative values; the more negative the value, the greater the degree of deformation and the better the function. Strain values were separated into normal (more negative than $-21 \%$ for RV and more negative than $-17 \%$ for $L V$ ), mild/moderately impaired ( -21 to $-13 \%$ for RV and -17 to $-10 \%$ for LV) and severely abnormal (less negative than $-13 \%$ for RV and less negative than $-10 \%$ for $L V)$. A consensus on normal values for strain of the RV and LV has yet to be defined primarily due to vendor differences in analysis methods [17]. The cutoff values chosen in this study are based on normal subjects at our institution [18] and on meta-analysis of normal subjects [19], and are similar to recent studies investigating LV ischemia [20] and pulmonary hypertension [21] as well as analysis of our sample group: receiver operating curve, interquartile range and logistic regression analysis. 


\section{a}

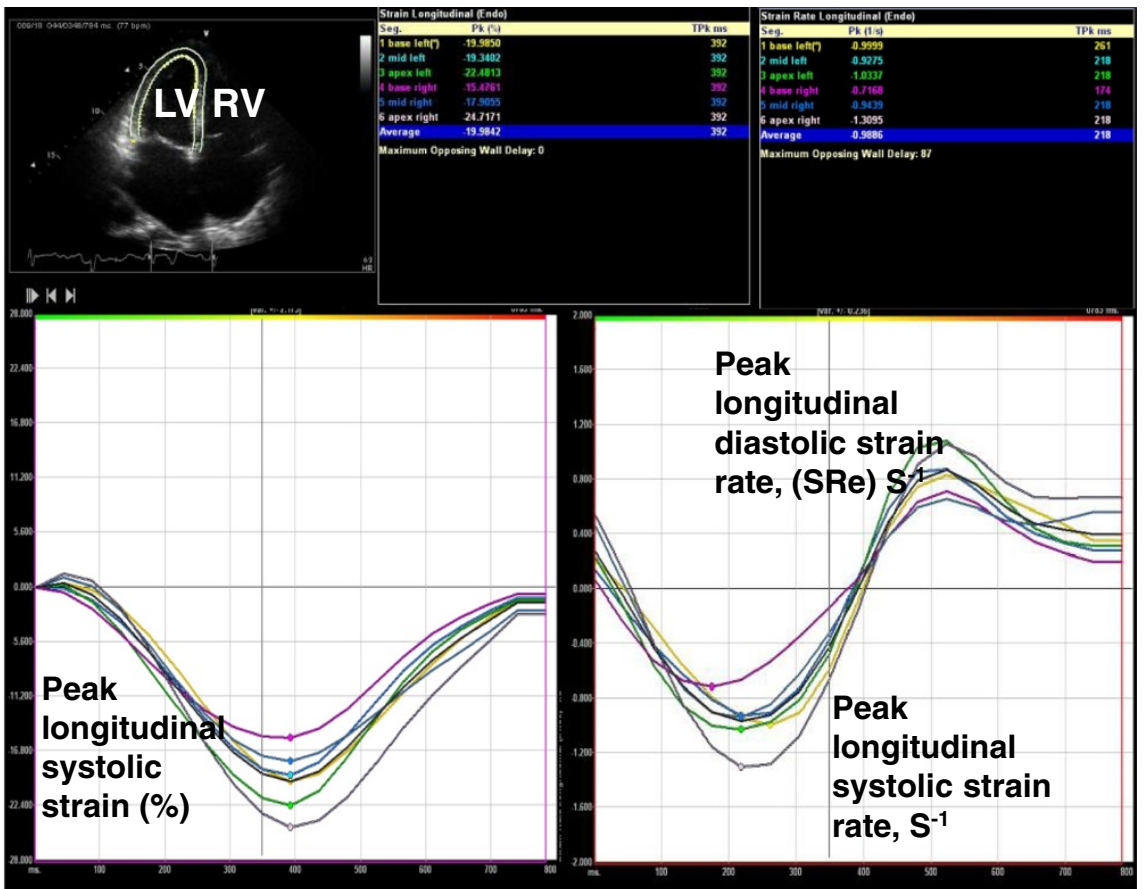

b

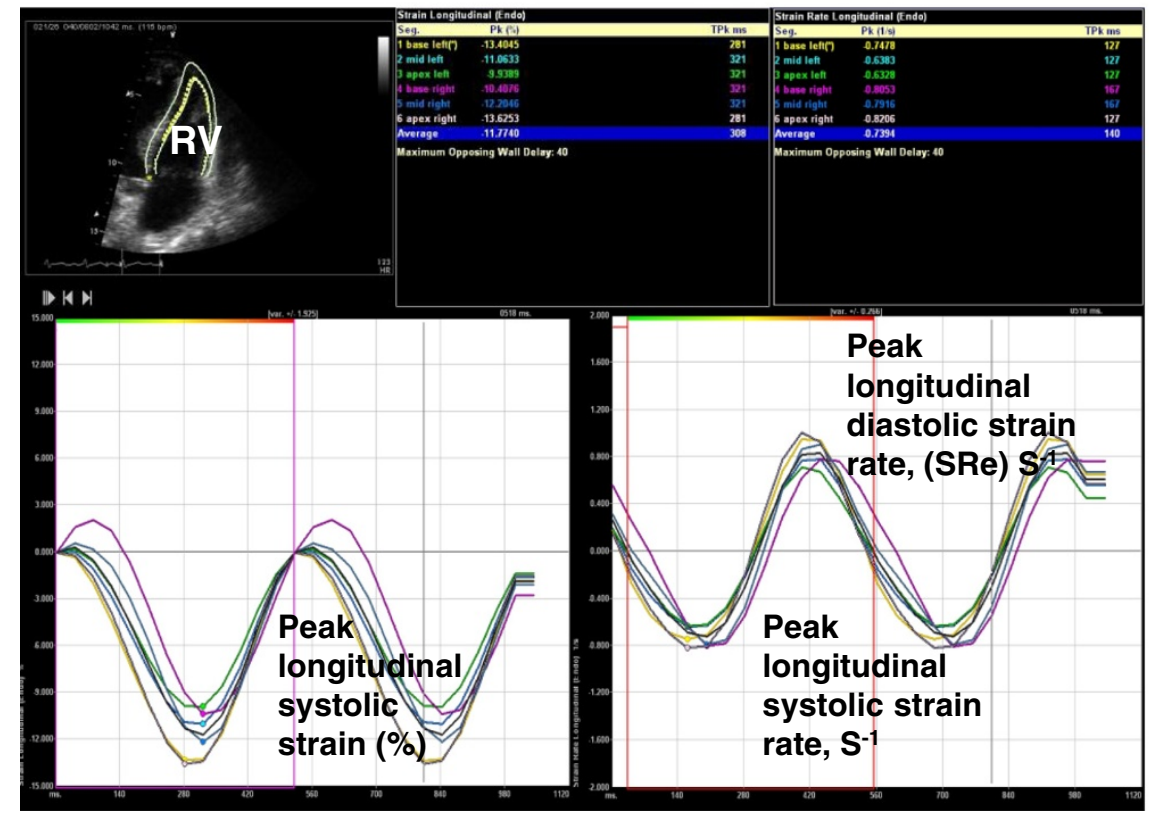

Figure 1 Longitudinal strain and strain rate curves. (a) Representative recording for apical four-chamber longitudinal strain and strain rate curves for a patient with normal left ventricle (LV) systolic function. Echo image displayed in Mayo format: left, LV; right, right ventricle (RV). Negative strain values indicate tissue contraction. Strain rate determined by change in strain over time. (b) Representative recording for apical four-chamber RV longitudinal strain and strain rate curves for a patient with abnormal RV systolic function. Echo image displayed in Mayo format: left, LV; right, RV. RV free wall longitudinal strain determined by the average of base, mid and apical free wall segments.

\section{Statistical analysis}

Statistical analysis was performed with JMP version 9.0.1 (SAS Institute Inc., Cary, NC, USA). Continuous variables are expressed as mean \pm standard deviation or median with interquartile range and were analyzed between groups using analysis of variance. Categorical variables are expressed as the number and percentage with comparisons by Pearson's chi-square analysis or Fisher's exact test. All probability values are two-sided and of $P \leq 0.05$ was considered significant. Univariate and multivariate logistic regression analyses were used to assess the association between risk factors and mortality. Discriminatory performance is assessed by odds 
ratio, 95\% confidence interval and area under the receiver operating characteristic curve. Multivariate models were developed with stepwise inclusion and exclusion at a significance level of 0.1 and by consideration of variables that were clinically relevant.

\section{Results}

Of 106 patients who were enrolled at our institution during the 18-month study period with severe sepsis or septic shock, 60 patients were included in our observational study. Of those excluded, 21 patients $(20 \%)$ had supraventricular arrhythmia and 14 patients $(13 \%)$ had insufficient image quality for STE analysis (10 of the 14 were mechanically ventilated). The mean age was 62 years $( \pm 15)$ with $50 \%$ female, $67 \%$ alive at 30 days $(n=$ $40)$ and $52 \%$ alive at 6 months $(n=31)$ (Table 1$)$. The SOFA score, arterial partial pressure of oxygen/fraction of inspired oxygen ratio, partial pressure of carbon dioxide and lactate levels were significantly worse in nonsurvivors at 30 days. The SOFA score was also significantly higher in nonsurvivors at 6 months. Thirty-nine patients (65\%) were mechanically ventilated at the time of imaging; at 30 days a greater portion of these patients were alive (21 of 39 patients), but only 15 of the 39 were alive at 6 months. No difference was seen in comorbidities between the patient groups.

\section{Echocardiographic analysis}

There was no difference seen between survivors and nonsurvivors in any standard echocardiography measure of ventricle size or function at 30 days or 6 months, or in their peak systolic pulmonary artery pressures (Tables 2 and 3 and Figure 2). There was a significant difference in RV free wall strain between survivors and nonsurvivors at 6 months $(-19 \% \pm 5$ vs. $-16 \% \pm 6$, $P=0.02)$. There was no difference in survivors' $L V$ GLS or GLS rate compared with nonsurvivors.

The incidence of myocardial dysfunction was different based on the method of assessment (Table 4). Based on conventional assessment, 19 patients (32\%) had RV dysfunction, 20 patients (33\%) had LV dysfunction and 10 patients (17\%) had both LV and RV dysfunction. Based on strain analysis, 43 patients (72\%) had RV dysfunction, 36 patients (69\%) had LV dysfunction and 30 patients

Table 1 Baseline physiological and clinical data with comparison for survival at 30 days and 6 months

\begin{tabular}{|c|c|c|c|c|c|}
\hline \multirow[t]{2}{*}{ Characteristic } & \multirow[t]{2}{*}{ Baseline } & \multicolumn{2}{|c|}{ 30-day mortality } & \multicolumn{2}{|c|}{ 6-month mortality } \\
\hline & & Survivors & Nonsurvivors & Survivors & Nonsurvivors \\
\hline Mortality & 60 & $40(67 \%)$ & $20(33 \%)$ & $31(52 \%)$ & $29(48 \%)$ \\
\hline \multicolumn{6}{|l|}{ Physiology } \\
\hline Age (years) & $62 \pm 15$ & $60 \pm 16$ & $65 \pm 13$ & $60 \pm 17$ & $65 \pm 13$ \\
\hline Female (\%) & 50 & 30 & 20 & 21.7 & 28.3 \\
\hline SOFA score & $11 \pm 4$ & $10 \pm 4^{*}$ & $13 \pm 3^{*}$ & $10 \pm 4^{*}$ & $12 \pm 4^{*}$ \\
\hline MAP $(\mathrm{mmHg})$ & $62 \pm 13$ & $63 \pm 15$ & $60 \pm 8$ & $63 \pm 13$ & $61 \pm 61$ \\
\hline Hemoglobin (g/dl) & $10.1 \pm 1.6$ & $10.2 \pm 1.6$ & $9.8 \pm 1.6$ & $10.4 \pm 1.6$ & $9.7 \pm 1.5$ \\
\hline NE dose ( $\mu \mathrm{g} / \mathrm{kg} /$ minute) & $0.2(0.06$ to 0.34$)$ & 0.15 (0.04 to 0.475$)$ & $0.225(0.08$ to 0.32$)$ & $0.18(0.07$ to 0.5$)$ & $0.2(0.1$ to 0.3$)$ \\
\hline Vasopressin (u/minute) & 0.04 (0.03 to 0.04$)$ & 0.04 (0.03 to 0.04$)$ & 0.04 (0.03 to 0.04$)$ & 0.04 (0.03 to 0.04) & 0.04 (0.03 to 0.04$)$ \\
\hline $\mathrm{ScvO}_{2}(\%)$ & $72 \pm 11$ & $70 \pm 13$ & $75 \pm 8$ & $72 \pm 11$ & $72 \pm 12$ \\
\hline $\mathrm{PaO}_{2} / \mathrm{FiO}_{2}(\mathrm{mmHg})$ & 195 (128 to 290) & $247(153 \text { to } 310)^{*}$ & 163.5 (113 to 199$)^{*}$ & 248.5 (76 to 300$)$ & 175 (124 to 260) \\
\hline $\mathrm{pCO}_{2}(\mathrm{mmHg})$ & $40 \pm 12$ & $38 \pm 9 *$ & $45 \pm 14^{*}$ & $38 \pm 11$ & $43 \pm 2$ \\
\hline $\mathrm{pH}$ & $7.29 \pm 0.1$ & $7.3 \pm 0.1$ & $7.27 \pm 0.1$ & $7.3 \pm 0.1$ & $7.29 \pm 0.1$ \\
\hline Lactate (mmol/l) & $3 \pm 2.8$ & $2.4 \pm 0.4^{*}$ & $4.2 \pm 0.6^{*}$ & 1.45 (1 to 3.78$)$ & $2.4(1.4$ to 4.2$)$ \\
\hline Creatinine (mg/dl) & $1.9 \pm 1$ & $2.1 \pm 1.2$ & $1.6 \pm 0.7$ & $1.84 \pm 0.9$ & $2 \pm 1.2$ \\
\hline Troponin T (ng/ml) & $0.03(0.01$ to 0.16$)$ & $0.03(0.01$ to 0.2$)$ & 0.03 (0.01 to 0.12$)$ & 0.025 (0.01 to 0.2) & $0.03(0.01$ to 0.1$)$ \\
\hline \multicolumn{6}{|l|}{ Clinical } \\
\hline Respiratory issues & $18(30 \%)$ & 12 & 6 & 7 & 11 \\
\hline Coronary artery disease & $8(13 \%)$ & 7 & 1 & 3 & 5 \\
\hline Chronic renal failure & $7(12 \%)$ & 5 & 2 & 4 & 3 \\
\hline Acute kidney injury & $25(42 \%)$ & 17 & 8 & 12 & 13 \\
\hline Mechanical ventilation & $39(65 \%)$ & $21^{*}$ & $18^{*}$ & $15^{*}$ & $24^{*}$ \\
\hline
\end{tabular}

Data presented as $n$ (\%), mean \pm standard deviation or median (interquartile range). ${ }^{*} P<0.05$ by analysis of variance. MAP, mean arterial pressure; NE, noradrenaline; $\mathrm{pCO}_{2}$, partial pressure of carbon dioxide; $\mathrm{PaO}_{2} / \mathrm{FiO}_{2}$, arterial partial pressure of oxygen/fraction of inspired oxygen ratio; ScvO ${ }_{2}$, central venous oxygen saturation; SOFA, Sequential Organ Failure Assessment. 
Table 2 Echocardiography data at baseline and compared for survival at 30 days and 6 months

\begin{tabular}{|c|c|c|c|c|c|}
\hline \multirow[t]{2}{*}{ Characteristic } & \multirow[t]{2}{*}{ Baseline } & \multicolumn{2}{|c|}{ 30-day mortality } & \multicolumn{2}{|c|}{ 6-month mortality } \\
\hline & & Survivors & Nonsurvivors & Survivors & Nonsurvivors \\
\hline \multicolumn{6}{|l|}{ Structure } \\
\hline RV basal length (mm) & $39 \pm 7$ & $40 \pm 8$ & $38 \pm 5$ & $40 \pm 8$ & $38 \pm 6$ \\
\hline RV mid length (mm) & $33 \pm 7$ & $33 \pm 7$ & $33 \pm 5$ & $34 \pm 7$ & $33 \pm 6$ \\
\hline RV longitudinal length (mm) & $75 \pm 9$ & $75 \pm 10$ & $74 \pm 8$ & $76 \pm 10$ & $73 \pm 8$ \\
\hline LV diastolic diameter (mm) & $47 \pm 5$ & $47 \pm 6$ & $48 \pm 4$ & $47 \pm 1$ & $48 \pm 5$ \\
\hline LV systolic diameter (mm) & $32 \pm 7$ & $33 \pm 7$ & $30 \pm 5$ & $33 \pm 7$ & $31 \pm 6$ \\
\hline \multicolumn{6}{|l|}{ Ventricular function } \\
\hline RV FAC (\%) & $40 \pm 10$ & $40 \pm 10$ & $39 \pm 10$ & $40 \pm 8$ & $39 \pm 11$ \\
\hline Lateral tricuspid annular TDI velocity (cm/second) & $15 \pm 5$ & $14 \pm 5$ & $17 \pm 5$ & $13 \pm 4$ & $16 \pm 6$ \\
\hline Cardiac index $\left(1 /\right.$ minute $\left./ \mathrm{m}^{2}\right)$ & $3.5 \pm 1.5$ & $3.5 \pm 1.7$ & $3.5 \pm 1.2$ & $3.5 \pm 1.4$ & $3.4 \pm 1.7$ \\
\hline SVI $\left(\mathrm{cm}^{3} / \mathrm{m}^{2}\right)$ & $37 \pm 15$ & $37 \pm 16$ & $38 \pm 13$ & $39 \pm 14$ & $35 \pm 16$ \\
\hline LV ejection fraction (\%) & $57 \pm 16$ & $56 \pm 17$ & $60 \pm 13$ & $55 \pm 15$ & $59 \pm 16$ \\
\hline \multicolumn{6}{|l|}{ Other parameters } \\
\hline Echo assessed SPAP (mmHg) & $42 \pm 15$ & $41 \pm 14$ & $44 \pm 17$ & $39 \pm 14$ & $46 \pm 15$ \\
\hline
\end{tabular}

Data presented as mean \pm standard deviation. FAC, fractional area change; LV, left ventricle; RV, right ventricle; TDI, tissue Doppler imaging; SVI, stroke volume index; SPAP, peak systolic pulmonary artery pressure.

(50\%) had both LV and RV strain dysfunction. When subgroups were created based on severity of dysfunction, strain function analysis also revealed a greater portion of patients with severe RV or LV dysfunction.

Analysis of variance of the association between 6month mortality and the RV strain dysfunction subgroups was significant $(P<0.001)$. Separate analysis within these groups exposed those patients with severe RV strain dysfunction as having the statistically significant association (Table 5). Multivariate analysis (Table 6) showed that severe RV free wall strain dysfunction remained an independent predictor of outcome at 6 months, accounting for mechanical ventilation $(P=0.03)$. This subgroup was also associated with a greater severity of disease (SOFA score), lower arterial partial pressure of oxygen/fraction of inspired oxygen ratios, mechanical ventilation, worse LV GLS, reduced RV FAC, higher echo-based right atrial pressures, lower tricuspid velocity, and higher echo-based peak systolic pulmonary artery pressure (Figure 3). Furthermore, there was a tendency towards higher levels of lactate. There was no association with RV dimensions. By comparison, RV systolic functional assessment by FAC was only associated with reduced LV GLS, and increased echo-based right atrial and RV systolic pressures. KaplanMeier curves show severe RV free wall longitudinal strain dysfunction was associated with 1-year mortality $(P<0.001)$ due to all patients in this subgroup dying before 6 months (Figure 4). Those with mild/moderate RV strain dysfunction and normal RV strain function had similar 1-year survival estimates $(57.1 \%$ and $54.9 \%$ respectively).

Pulmonary hypertension was not an exclusion criterion, but no patient had a formal diagnosis at time of enrollment. Fifteen patients had echocardiograms performed in the preceding 6 months to admission and four of these patients had peak systolic pulmonary artery pressure estimation $>36 \mathrm{mmHg}$, considered raised pulmonary pressure by the American Society of Echocardiography [16]. Although no significant RV dysfunction was reported, there may have been unrecognized prior RV strain dysfunction.

Table 3 Baseline ventricular longitudinal strain with comparison for survival at 30 days and 6 months

\begin{tabular}{|c|c|c|c|c|c|}
\hline \multirow[t]{2}{*}{ Characteristic } & \multirow[t]{2}{*}{ Baseline } & \multicolumn{2}{|c|}{ 30-day mortality } & \multicolumn{2}{|c|}{ 6-month mortality } \\
\hline & & Survivors & Nonsurvivors & Survivors & Nonsurvivors \\
\hline RV free wall strain (\%) & $-17.7 \pm 5.5$ & $-18.1 \pm 5.4$ & $-16.9 \pm 5.6$ & $-19.3 \pm 4.9^{*}$ & $-16.0 \pm 5.7^{*}$ \\
\hline RV free wall strain rate (1/second) & $-1.14 \pm 0.4$ & $-1.14 \pm 0.33$ & $-1.14 \pm 0.4$ & $-1.19 \pm 0.3$ & $-1.09 \pm 0.4$ \\
\hline LV GLS (\%) & $-14.1 \pm 4.2$ & $-13.92 \pm 4.2$ & $-14.6 \pm 4.3$ & $-14 \pm 4$ & $-14.28 \pm 4.6$ \\
\hline LV GLS rate (1/second) & $-0.89 \pm 0.3$ & $-0.86 \pm 0.2$ & $-0.96 \pm 0.3$ & $-0.86 \pm 0.2$ & $-0.93 \pm 0.3$ \\
\hline
\end{tabular}

Data presented as mean \pm standard deviation. ${ }^{*} P<0.05$ by analysis of variance. GLS, global longitudinal strain; LV, left ventricle; RV, right ventricle. 
(A) Left ventricle

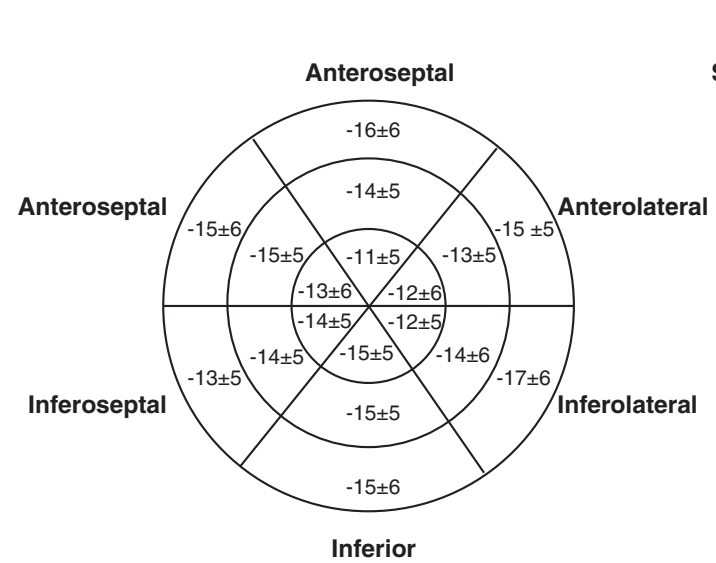

(B) Right ventricle

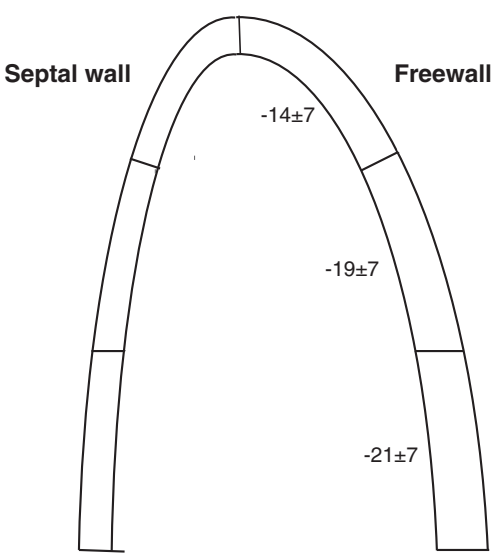

Figure 2 Left and right ventricle segmental longitudinal strain values. (A) Graphical representation of left ventricle segmental longitudinal strain with three concentric circles representing apex (inner circle), mid and base (outer circle). (B) Graphical representation of right ventricle segmental free wall longitudinal strain. Data presented as mean \pm standard deviation.

Excluding these patients from the analysis did not alter the relationship between 6-month mortality and RV free wall strain dysfunction.

\section{Measurement variability}

Blinded interrater variability for STE analysis was assessed by JNS on a random $10 \%$ subgroup. Bland-Altman analysis demonstrated good intraobserver and interobserver agreement. The interobserver and intraobserver mean difference ( \pm standard deviation) were respectively: RV free wall longitudinal strain, $-2( \pm 1.2)$ and $-1.4( \pm 0.9)$; RV free wall longitudinal strain rate, $-0.3( \pm 0.1)$ and $-0.1( \pm 0.05)$; LV GLS, $-0.9( \pm 0.9 \%)$ and $-0.8( \pm 0.5)$; and LV GLS rate, $-0.1( \pm 0.05)$ and $-0.1( \pm 0.05)$.

Table 4 Univariate analysis of systolic dysfunction and association with 30-day and 6-month mortality

\begin{tabular}{|c|c|c|c|c|c|c|c|c|}
\hline & & \multirow[t]{2}{*}{ Baseline } & \multicolumn{3}{|c|}{ 30-day mortality } & \multicolumn{3}{|c|}{ 6-month mortality } \\
\hline & & & Survivors & Nonsurvivors & $P$ value & Survivors & Nonsurvivors & $P$ value \\
\hline \multicolumn{9}{|c|}{ Strain analysis } \\
\hline \multirow[t]{4}{*}{ RV free wall strain } & RV dysfunction & 43/60 (72\%) & & & 0.33 & & & 0.001 \\
\hline & $\cdot<-21$ & 17 & 13 & 4 & & 12 & 5 & \\
\hline & $\cdot-13$ to -21 & 31 & 21 & 10 & & 18 & 13 & \\
\hline & $\cdot>-13$ & 12 & 6 & 6 & & 1 & 11 & \\
\hline \multirow[t]{4}{*}{ GLS } & LV dysfunction & $36 / 52(69 \%)$ & & & 0.40 & & & 0.44 \\
\hline & $\cdot<-17$ & 16 & 9 & 7 & & 7 & 9 & \\
\hline & $\cdot-10$ to -17 & 25 & 19 & 6 & & 16 & 9 & \\
\hline & $\cdot>-10$ & 11 & 8 & 3 & & 6 & 5 & \\
\hline \multicolumn{9}{|c|}{ Standard echocardiographic analysis } \\
\hline \multicolumn{2}{|l|}{ RV dysfunction } & $19 / 60(32 \%)$ & & & 0.26 & & & 0.17 \\
\hline \multicolumn{2}{|l|}{ Mild } & 12 & 6 & 6 & & 3 & 9 & \\
\hline \multicolumn{2}{|l|}{ Moderate } & 4 & 3 & 1 & & 3 & 1 & \\
\hline \multicolumn{2}{|l|}{ Severe } & 3 & 3 & 0 & & 2 & 1 & \\
\hline \multicolumn{2}{|l|}{ LV dysfunction } & $20 / 60(33 \%)$ & & & 0.50 & & & 0.55 \\
\hline \multicolumn{2}{|c|}{ Mild ( $E F=45$ to $55 \%)$} & 8 & 5 & 3 & & 4 & 4 & \\
\hline \multicolumn{2}{|c|}{ Moderate ( $E F=35$ to 45\%) } & 8 & 7 & 1 & & 6 & 2 & \\
\hline \multicolumn{2}{|l|}{ Severe $(E F<35 \%)$} & 4 & 3 & 1 & & 2 & 2 & \\
\hline
\end{tabular}

Data presented as $n$ (\%). Strain is a measure of myocardial deformation and is described in negative values; greater negative numbers indicate better function. $\mathrm{EF}$, ejection fraction; GLS, global longitudinal strain; LV, left ventricle; RV, right ventricle. 
Table 5 Odds ratios for subsets of right ventricular free wall strain versus 6 -month mortality

\begin{tabular}{|c|c|c|c|}
\hline Subgroup & $\begin{array}{l}\text { Odds } \\
\text { ratio }\end{array}$ & $\begin{array}{l}95 \% \text { confidence } \\
\text { interval }\end{array}$ & $P$ value \\
\hline $\begin{array}{l}\text { Severe vs. mild/moderate } \\
\text { (strain }>-13 \text { vs. }-13 \text { to }-21 \text { ) }\end{array}$ & 15.23 & 2.5 to 296.27 & 0.002 \\
\hline $\begin{array}{l}\text { Severe vs. normal (strain }>-13 \\
\text { vs. }<-21 \text { ) }\end{array}$ & 26.4 & 3.7 to 553.78 & $<0.001$ \\
\hline $\begin{array}{l}\text { Mild/moderate vs. normal } \\
\text { (strain }-13 \text { to }-21 \text { vs. }>-21 \text { ) }\end{array}$ & 1.73 & 0.5 to 6.56 & 0.4 \\
\hline
\end{tabular}

\section{Discussion}

In this observational cohort study of 60 patients with severe sepsis or septic shock we demonstrated: frequent biventricular systolic dysfunction, occasionally severe, occurring within 24 hours of diagnosis; that STE is a more sensitive method of assessing systolic dysfunction than conventional echocardiography; and that severe RV dysfunction assessed by STE (RV free wall strain) is associated with a worse prognosis.

The use of STE in the noncritically ill population is increasing because most modern high-end echocardiography machines have the software capability. These advanced machines are becoming increasingly available in the ICU and it is suggested that STE may unmask systolic dysfunction not seen by standard echocardiographic assessment [11]. Indeed, a greater portion of the patients in our study were identified as having systolic dysfunction of both the RV and LV when assessed by STE as compared with conventional echocardiography. STE assessment of the LV GLS adds prognostic value in heart failure [22] and myocardial ischemia [20], and RV free wall strain analysis in pulmonary vascular disease trumps all other measures of RV function in the independent prediction of clinical deterioration and mortality and may help guide therapy [21,23-25]. In our septic population, RV free wall strain was the only parameter associated with mortality.

STE is dependent on adequate image quality, and studies in the noncritically ill report a 7 to $9 \%$ suboptimal image quality for STE analysis [18,20]. Imaging in the critically ill can be difficult and $13 \%$ of our patients were excluded due to poor image quality; however, STE was still feasible in the majority of our patients with

Table 6 Multivariate analysis of severe right ventricle strain dysfunction and mechanical ventilation with 6-month mortality

\begin{tabular}{lccc}
\hline & \multicolumn{3}{c}{ 6-month mortality } \\
\cline { 2 - 4 } Parameter & Odds ratio & $\begin{array}{c}\mathbf{9 5 \%} \text { confidence } \\
\text { interval }\end{array}$ & $\boldsymbol{P}$ value \\
\hline $\begin{array}{l}\text { Severe right ventricle } \\
\text { strain dysfunction }\end{array}$ & 11.9 & 1.9 to 232 & $\mathbf{0 . 0 3}$ \\
\begin{tabular}{l} 
Mechanical ventilation \\
\hline
\end{tabular} & 3.0 & 0.88 to 11.2 & 0.09 \\
\hline
\end{tabular}

adequate images. However, the difficulty in imaging analysis may explain why the interobserver variability in our study was slightly higher compared with others [18].

Myocardial dysfunction in sepsis is caused by a variety of factors, including direct effect by the infectious process (inflammatory mediators, bacterial toxins, and/or myocardial mitochondrial dysfunction), decreased myocardial perfusion, interventricular dependence and raised pulmonary pressures from acute lung injury, hypoxia, hypercarbia and atelectasis. Evaluation of myocardial contractile function by echocardiography is challenging, particularly for the RV due to its complex geometry, which makes volumetric assessment difficult. Several studies have found RV systolic dysfunction early in the course of sepsis to be associated with increased mortality [26-28]. However, other studies have found no significant difference between survivors and nonsurvivors [2,29]. A similar debate exists concerning LV dysfunction and outcomes [30-33]. A recent meta-analysis failed to find any evidence of differences in RV or LV function related to mortality [34].

The association between 6-month mortality and severe RV free wall strain dysfunction highlights the importance of RV function analysis in the prognosis of the critically ill patient, and this supports studies in other populations such as patients with acute respiratory distress syndrome [35]. All of the patients in our study with severe RV strain dysfunction died within 6 months of admission to the ICU with severe sepsis, potentially due to being sicker on admission (higher SOFA scores), being more likely to be on mechanical ventilation, or having worse gas exchange, worse LV GLS function and higher echo-based RV systolic pulmonary pressure estimation than patients without severe RV dysfunction. A myriad of factors are at play, and the RV can be affected by all of them - RV dysfunction is therefore likely to be a marker of disease severity as much as being a factor behind the association with poor outcomes. However, early recognition of RV dysfunction may help in the care of the critically ill patient with sepsis and may place emphasis on limiting factors that are potentially involved, such as fluid overload, high positive end-expiratory pressure levels, atelectasis, hypoxia or hypercarbia, amongst others.

\section{Limitations}

This study is observational in nature and has a limited number of patients, and the imaging was not optimized for STE (for example, improved endocardial border definition, RV centric views, and so forth). One cannot exclude that weaker associations may be statistically significant in a cohort with a larger sample size. Repeated imaging and further STE analysis were not performed. Further dysfunction that would be seen by standard echo parameters may have occurred at a later 

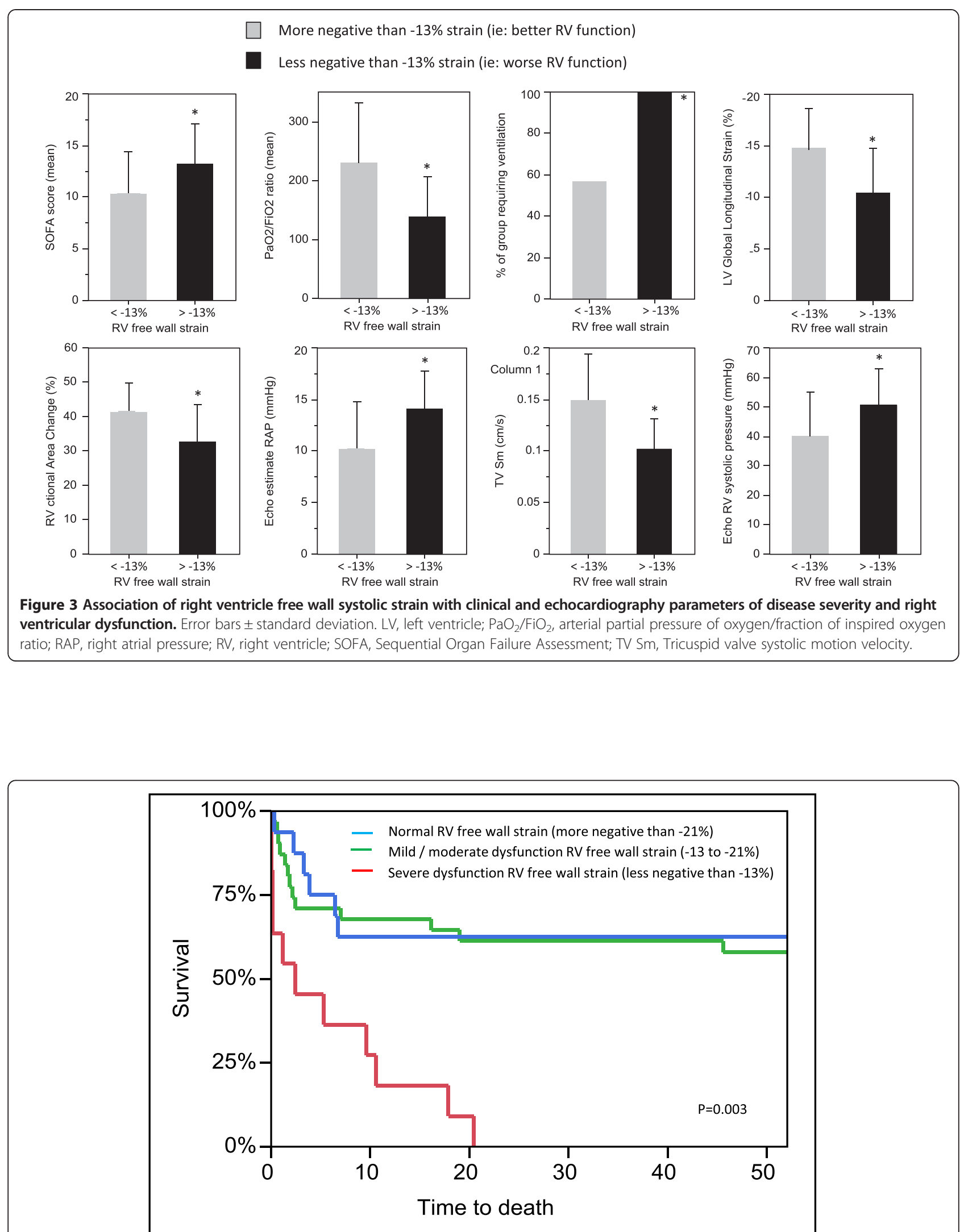

Figure 4 Kaplan-Meier 1-year survival curves based on right ventricle free wall strain. RV, right ventricle. 
stage. Larger, prospective studies with imaging focused for STE optimization and follow-up echocardiography STE analysis could be considered in future.

There are several drawbacks to current STE analysis that limit its clinical utility in the ICU at this time: STE requires adequate image quality, which can be challenging particularly in the mechanically ventilated patient (10 of the 14 patients excluded due to inadequate image quality), STE is time consuming to perform, and normal values have been difficult to elucidate partly due to vendor differences in the software algorithms [19]. Our cutoff values between normality, mild and moderate abnormality and severe abnormality are similar to recent studies on large populations of both normal controls $[18,19]$ and patients with cardiac dysfunction [25]. With technology advancing and expert groups such as the American Society of Echocardiography and the European Association of Echocardiography calling for concordance on vendor STE software analysis, and as the use of STE becomes more widespread, perhaps strain will become a more standard measurement in the future [17].

\section{Conclusions}

STE unmasks systolic dysfunction unrecognized with conventional echocardiography in patients with severe sepsis or septic shock. RV dysfunction assessed by strain appears to be correlated with worse late outcomes, especially if the dysfunction is severe. LV dysfunction assessed either by conventional imaging or STE does not appear to correlate with survival in sepsis.

\section{Key messages}

- STE unmasks systolic dysfunction unrecognized with conventional echocardiography in patients with severe sepsis or septic shock.

- Severe right ventricular strain dysfunction is associated with worse prognosis.

- LV dysfunction assessed by standard echocardiography or STE is not associated with early or late outcome.

\footnotetext{
Abbreviations

FAC: fractional area change; GLS: global longitudinal strain; LV: left ventricle; RV: right ventricle; SOFA: Sequential Organ Failure Assessment; STE: speckle tracking echocardiography
}

\section{Competing interests}

The authors declare that they have no competing interests.

\section{Authors' contributions}

SRO, JNP, MM, SG, JNS, GCK and JKO contributed to data acquisition and take responsibility for the integrity and accuracy of the data and analysis. SRO, JNP, GCK and JKO had access to the data, and contributed to study conception and design, statistical analysis and preparation of the manuscript. MM and SG contributed to study conception and design, and preparation of the manuscript. JNS contributed to data analysis and interpretation, and drafting of the manuscript. All authors read and approved the final manuscript.

\section{Author details}

'Division of Cardiovascular Diseases, Mayo Clinic, 200 First St SW, Rochester, MN 55905, USA. ${ }^{2}$ Department of Intensive Care, Nepean Hospital, Sydney, Australia. ${ }^{3}$ Department of Anesthesiology, Mayo Clinic, 200 First St SW, Rochester, MN 55905, USA. ${ }^{4}$ Hyogo College of Medicine, Nishinomiya, Hyogo, Japan.

Received: 4 December 2013 Accepted: 5 June 2014

Published: 11 July 2014

\section{References}

1. Celes MR, Prado CM, Rossi MA: Sepsis: going to the heart of the matter. Pathobiology 2013, 80:70-86.

2. Pulido JN, Afessa B, Masaki M, Yuasa T, Gillespie S, Herasevich V, Brown DR, Oh JK: Clinical spectrum, frequency, and significance of myocardial dysfunction in severe sepsis and septic shock. JMCP 2012, 87:620-628.

3. Kimchi A, Ellrodt A, Berman D, Riedinger M, Swan H, Murata G: Right ventricular performance in septic shock: a combined radionuclide and hemodynamic study. J Am Coll Cardiol 1984, 4:945-951.

4. Vincent J-L, Rhodes A, Perel A, Martin GS, Rocca Della G, Vallet B, Pinsky MR, Hofer CK, Teboul J-L, de Boode W-P, Scolletta S, Vieillard-Baron A, De Backer D, Walley KR, Maggiorini M, Singer M: Clinical review: Update on hemodynamic monitoring - a consensus of 16. Crit Care 2011, 15:229.

5. Huang SJ, Orde S: From speckle tracking echocardiography to torsion. Curr Opin Crit Care 2013, 19:250-257.

6. Langeland S, Wouters PF, Claus P, Leather HA, Bijnens B, Sutherland GR, Rademakers FE, D'hooge J: Experimental assessment of a new research tool for the estimation of two-dimensional myocardial strain. Ultrasound Med Biol 2006, 32:1509-1513.

7. Migrino RQ, Aggarwal D, Konorev E, Brahmbhatt T, Bright M, Kalyanaraman B: Early detection of doxorubicin cardiomyopathy using two-dimensional strain echocardiography. Ultrasound Med Biol 2008, 34:208-214.

8. Bellavia D, Pellikka P, Dispenzieri A, Scott C, Al-Zahrani G, Grogan M, Pitrolo F, Oh J, Miller F: Comparison of right ventricular longitudinal strain imaging, tricuspid annular plane systolic excursion, and cardiac biomarkers for early diagnosis of cardiac involvement and risk stratification in primary systematic (AL) amyloidosis: a 5-year cohort study. Eur Heart J Cardiovasc Imaging 2012, 13:680-689.

9. Bellavia D, Abraham TP, Pellikka PA, Al-Zahrani GB, Dispenzieri A, Oh JK, Bailey KR, Wood CM, Novo S, Miyazaki C, Miller FA: Detection of left ventricular systolic dysfunction in cardiac amyloidosis with strain rate echocardiography. J Am Soc Echocardiogr 2007, 20:1194-1202.

10. Shahul S, Rhee J, Hacker MR, Gulati G, Mitchell JD, Hess P, Mahmood F, Arany Z, Rana S, Talmor D: Subclinical left ventricular dysfunction in preeclamptic women with preserved left ventricular ejection fraction: a 2D speckle-tracking imaging study. Circ Cardiovasc Imaging 2012, 5:734-739.

11. Basu S, Frank LH, Fenton KE, Sable CA, Levy RJ, Berger JT: Two-dimensional speckle tracking imaging detects impaired myocardial performance in children with septic shock, not recognized by conventional echocardiography. Pediatr Crit Care Med 2012, 13:259-264.

12. Buckberg G, Hoffman JIE, Mahajan A, Saleh S, Coghlan C: Cardiac mechanics revisited: the relationship of cardiac architecture to ventricular function. Circulation 2008, 118:2571-2587.

13. Rushmer R, Crystal D: Changes in configuration of the ventricular chambers during the cardiac cycle. Circulation 1951, 4:211-218.

14. Bone RC, Balk RA, Cerra FB, Dellinger RP, Fein AM, Knaus WA, Schein RM, Sibbald WJ: Definitions for sepsis and organ failure and guidelines for the use of innovative therapies in sepsis, the ACCP/SCCM Consensus Conference Committee. American College of Chest Physicians/Society of Critical Care Medicine. Chest 1992, 101:1644-1655.

15. Lang RM, Bierig M, Devereux RB, Flachskampf FA, Foster E, Pellikka PA, Picard MH, Roman MJ, Seward J, Shanewise JS, Solomon SD, Spencer KT, Sutton MSJ, Stewart WJ, Chamber Quantification Writing Group; American Society of Echocardiography's Guidelines and Standards Committee: European Association of Echocardiography: Recommendations for chamber quantification: a report from the American Society of 
Echocardiography's Guidelines and Standards Committee and the Chamber Quantification Writing Group, developed in conjunction with the European Association of Echocardiography, a branch of the European Society of Cardiology. J Am Soc Echocardiogr 2005, 18:1440-1463.

16. Rudski LG, Lai WW, Afilalo J, Hua L, Handschumacher MD, Chandrasekaran K, Solomon SD, Louie EK, Schiller NB: Guidelines for the echocardiographic assessment of the right heart in adults: a report from the American Society of Echocardiography endorsed by the European Association of Echocardiography, a registered branch of the European Society of Cardiology, and the Canadian Society of Echocardiography. J Am Soc Echocardiogr 2010, 23:685-713. quiz 786-788.

17. Marwick TH: Will standardization make strain a standard measurement? J Am Soc Echocardiogr 2012, 25:1204-1206.

18. Fine NM, Shah AA, Han I-Y, Yu Y, Hsiao J-F, Koshino Y, Saleh HK, Miller FA, Oh JK, Pellikka PA, Villarraga HR: Left and right ventricular strain and strain rate measurement in normal adults using velocity vector imaging: an assessment of reference values and intersystem agreement. Int J Cardiovasc Imaging 2013, 29:571-580.

19. Yingchoncharoen T, Agarwal S, Popović ZB, Marwick TH: Normal ranges of left ventricular strain: a meta-analysis. J Am Soc Echocardiogr 2013, 26:185-191.

20. Ersbø\|l M, Valeur N, Mogensen UM, Andersen MJ, Møller JE, Velazquez EJ, Hassager C, Søgaard P, Køber L: Prediction of all-cause mortality and heart failure admissions from global left ventricular longitudinal strain in patients with acute myocardial infarction and preserved left ventricular ejection fraction. J Am Coll Cardiol 2013, 61:2365-2373.

21. Sachdev A, Villarraga HR, Frantz RP, McGoon MD, Hsiao J-F, Maalouf JF, Ammash NM, McCully RB, Miller FA, Pellikka PA, Oh JK, Kane GC: Right ventricular strain for prediction of survival in patients with pulmonary arterial hypertension. Chest 2011, 139:1299-1309.

22. Cho G-Y, Marwick TH, Kim H-S, Kim M-K, Hong K-S, Oh D-J: Global 2-dimensional strain as a new prognosticator in patients with heart failure. J Am Coll Cardiol 2009, 54:618-624.

23. Hardegree EL, Sachdev A, Villarraga HR, Frantz RP, McGoon MD, Kushwaha SS, Hsiao J-F, McCully RB, Oh JK, Pellikka PA, Kane GC: Role of serial quantitative assessment of right ventricular function by strain in pulmonary arterial hypertension. Am J Cardio/ 2013, 111:143-148.

24. Haeck M, Scherptong R, Marsan N, Holman E, Schalij M, Bax J, Vliegen H, Delgado V: Prognostic value of right ventricular longitudinal peak systolic strain in patients with pulmonary hypertension. Circ Cardiovasc Imaging 2012, 5:628-636.

25. Fine NM, Chen L, Bastiansen PM, Frantz RP, Pellikka PA, Oh JK, Kane GC: Outcome prediction by quantitative right ventricular function assessment in 575 subjects evaluated for pulmonary hypertension. Circ Cardiovasc Imaging 2013, 6:711-721.

26. Liu D, Du B, Long Y, Zhao C, Hou B: Right ventricular function of patients with septic shock: clinical significance. Zhonghua wai ke za zhi 2000, 38:488-492.

27. Dhainaut J, Lanore J, Gournay J, Huyghebaert M, Brunet F, Villemant D, Monsallier J: Right ventricular dysfunction in patients with septic shock. Intensive Care Med 1988, 14:488-491.

28. Furian T, Aguiar C, Prado K, Ribeiro RVP, Becker L, Martinelli N, Clausell N, Rohde LE, Biolo A: Ventricular dysfunction and dilation in severe sepsis and septic shock: relation to endothelial function and mortality. J Crit Care 2012, 27:319. e9-319.e15.

29. Parker MM, McCarthy KE, Ognibene FP, Parrillo JE: Right ventricular dysfunction and dilatation, similar to left ventricular changes, characterize the cardiac depression of septic shock in humans. Chest 1990, 97:126-131.

30. Weng L, Liu Y, Zhou J, Guo X, Peng J, Hu X, Fang Q, Zhu W, Li H, Du B, Zhang S: Left ventricular systolic function and systolic asynchrony in patients with septic shock and normal left ventricular ejection fraction. Shock 2013, 40:175-181.

31. Parker MM, Shelhamer JH, Bacharach SL, Green MV, Natanson C, Frederick TM, Damske BA, Parrillo JE: Profound but reversible myocardial depression in patients with septic shock. Ann Intern Med 1984, 100:483-490.

32. Vieillard-Baron A, Caille V, Charron C, Belliard G, Page B, Jardin F: Actual incidence of global left ventricular hypokinesia in adult septic shock. Crit Care Med 2008, 36:1701-1706.
33. Micek ST, McEvoy C, McKenzie M, Hampton N, Doherty JA, Kollef MH: Fluid balance and cardiac function in septic shock as predictors of hospital mortality. Crit Care 2013, 17:R246.

34. Huang SJ, Nalos M, McLean AS: Is early ventricular dysfunction or dilatation associated with lower mortality rate in adult severe sepsis and septic shock? A meta-analysis. Crit Care 2013, 17:R96.

35. Boissier F, Katsahian S, Razazi K, Thille AW, Roche-Campo F, Leon R, Vivier E, Brochard L, Vieillard-Baron A, Brun-Buisson C, Mekontso Dessap A: Prevalence and prognosis of cor pulmonale during protective ventilation for acute respiratory distress syndrome. Intensive Care Med 2013, 39:1725-1733.

doi:10.1186/cc13987

Cite this article as: Orde et al:: Outcome prediction in sepsis: Speckle tracking echocardiography based assessment of myocardial function. Critical Care 2014 18:R149.

\section{Submit your next manuscript to BioMed Central and take full advantage of:}

- Convenient online submission

- Thorough peer review

- No space constraints or color figure charges

- Immediate publication on acceptance

- Inclusion in PubMed, CAS, Scopus and Google Scholar

- Research which is freely available for redistribution 